\title{
Karbürlü östemperlenmiş küresel grafitli dökme demirler
}

\author{
Gülcan TOKTAŞ", Alaaddin TOKTAŞ \\ Balıkesir Üniversitesi Mühendislik Fakültesi Makine Mühendisliği Bölümü Çağış Kampüsü-Balıkesir \\ Geliş Tarihi (Recived Date): 16.10.2017 \\ Kabul Tarihi (Accepted Date): 27.11.2017
}

\section{Özet}

Karbürlü östemperlenmiş küresel grafitli dökme demirler, üstün abrasif aşınma dirençlerinin yanında yeterli darbe tokluğuna da sahip olmaları nedeniyle son zamanlarda aşınma uygulamalarında dikkat çeken küresel grafitli dökme demir ailesinin en yeni üyelerinden biridir. Bu dökme demirlerin üretimi için yeni bir teknolojiye veya ek yatırıma ihtiyaç duyulmadiğından pek çok aşınma dirençli malzemeye nazaran imalat süreçleri daha kolay ve ucuzdur. Bu çalışmada karbürlü küresel grafitli dökme demirlerin bileşimleri, üretimleri, isıl işlemi, işlem sonucundaki içyapısı ve aşınma dayanımları detaylı olarak incelenmiştir. Çalışmanın sonucunda, maliyet ve darbe tokluğu göz önüne alındığında; bu dökme demirlerin aşınma performansının yüksek kromlu abrasif aşınma dirençli dökme demirlerinki ile mukayese edilebilir ölçüde olduğu görüllmüş̧ı̈̈r.

Anahtar Kelimeler: Karbürlü ÖKGDD, aşınma direnci, östemperleme.

\section{Carbidic austempered ductile irons}

\begin{abstract}
Carbidic austempered ductile iron, which attracts considerable attention in wear applications recently, due to its superior abrasive wear resistance and sufficient impact toughness, is the latest member of ductile iron family. A new technology and additional investment are not required for the production of these irons. So, the manufacturing process of these irons is easier and cheaper than that of many wear resistant materials. As a result, it is seen that the wear performance of these irons can be comparable with that of high $\mathrm{Cr}$ abrasive wear resistant irons, when considering cost efficiency and impact toughness.
\end{abstract}

\footnotetext{
"Gülcan TOKTAŞ, gzeytin@ balikesir.edu.tr, http://orcid.org/0000-0002-0455-2107

Alaaddin TOKTAS, atoktas@balikesir.edu.tr, http://orcid.org/0000-0002-9902-6969
} 
Keywords: Carbidic austempered ductile iron, wear resistance, austempering.

\section{Giriş}

Küresel grafitli dökme demir; ekonomik ve hızlı üretime, geniş alanda mekanik ve teknolojik özelliklere sahip olması sebebiyle 40'lı yıllardaki keşfinden günümüze dek pek çok uygulamada başarıyla kullanılmıştır. Eski geçmişine rağmen, bu dökme demir ile ilgili çalışmalar halen devam etmektedir. İlk önceleri bu çalışmalar sonucunda östemperleme işlemi ile östemperlenmiş küresel grafitli dökme demir (ÖKGDD) elde edilmiş, bu 1sıl işlem ile dökme demire daha geniş ve yüksek aralıklarda mukavemet ve aşınma dayanımı gibi üstün özellikler kazandırılmıştır.

ÖKGDD'ler, çelikler ile karşılaştırıldığında sadece yüksek mukavemet ve tokluk özellikleri ile değil aynı zamanda aşınmaya dirençli malzemeler olarak da önem kazanırlar. Isıl işlem parametreleri uygun seçildiğinde bu dökme demirler düşük ve yüksek gerilmeli abrasif aşınmaya karşı tatmin edici bir direnç gösterirler.

Pek çok endüstriyel makine parçası kullanımları esnasında aşınmaya maruz kalırlar. Malzeme kaybı açısından değerlendirildiğinde tarım, maden ve yapı endüstrisinde abrasif aşınma önemli bir aşınma çeşidi olarak karşımıza çıkar. Son yıllarda ağır aşınma şartlarında kullanılmak üzere, içyapısında serbest karbür içeren ÖKGDD'in yeni bir çeşidi geliştirilmiştir. Genellikle, karbürlü ÖKGDD; karbürlerin içyapıda termal veya mekanik olarak oluşturulduğu karbürlü KGDD'in uygun koşullarda östemperlenmesi ile elde edilir[1]. Karbürlerin varlığı darbe tokluğunu azaltırken, matrisi abrasif aşınmaya karşı ekstra dirençli kılmaktadır. Bazı durumlarda, karbürlü ÖKGDD'in abrasif aşınma direnci sertleştirilmiş ve temperlenmiş çelikler ve beyaz dökme demirler ile düşük üretim maliyeti açısından mukayese edilebilir [2]. Bu dökme demir maden endüstrisi, mühendislik makineleri, tarım makineleri, mühendislik yapıları, demiryolları gibi pek çok yapısal uygulamalarda gelecek vaat eden ve ekonomik bir mühendislik malzemesidir [3].

Aşınmaya karşı dirençli nispeten yeni bir malzeme olduğundan, karbürlü ÖKGDD üzerine yapılan çalışmalar hızla devam etmektedir. Hayrynen ve arkadaşları[4] karbürlü ÖKGDD tokluğunun abrasif aşınma dirençli dökme demirlerin tokluğundan daha üstün olduğunu, bu dökme demirlerin toklukla birlikte aşınma direnci gerektiren uygulamalarda başarıyla kullanılabileceği sonucuna varmışlardır. Laino ve arkadaşları[5] ÖKGDD'in yapısında karbür bulunduğunda aşınma direncinin aynı sıcaklıkta östemperlenen geleneksel ÖKGDD'e göre \%100 oranında artış gösterebileceğini ifade etmişlerdir. Cheng ve arkadaşları[6], östemperleme tuz banyosuna değişik oranlarda (\%0-\%3) çeşme suyu ilave ederek soğuma hızının iç yapıya etkisini incelemiş̧lerdir. Soğuma hızının ösferritik yapıya ve artık östenit miktarına önemli etkisinin olduğunu, yüksek miktarda su ilavesinin dökme demirin sertliğini arttırıp, darbe tokluğunu azalttığını bildirmişlerdir. Likhite ve arkadaşları[7] östenitleme sıcaklığının etkisini araştırdıkları çalışmalarında, $900^{\circ} \mathrm{C}$ 'de östenitleme ile östemperleme sonrası ince ösferritik matris içinde küçük dağılımlı karbürlerin oluştuğunu bildirmişlerdir. Düşük östenitleme sıcaklığının östenitin karbon miktarını azaltarak dönüşüm hızını arttırdığı ve ince taneli yap1 oluşturduğu sonucuna varmışlardır. Dhanapal ve arkadaşları[8] Taguchi yöntemi ile karbürlü ÖKGDD'de 
parametre optimizasyonu yaptıkları çalışmalarının sonucunda en önemli ve en önemsiz parametrelerin sirasıyla $\mathrm{Cr}$ miktarı ve östemperleme zamanı olduğu sonucuna varmışlardır. Ayrıca çalışmalarında Taguchi yöntemi ile hesapladıkları optimal parametrenin deney sonuçlarıyla uyuştuğu sonucuna varmışlardır.

Bu çalışma; aşınma dirençli nispeten yeni bir malzeme olan karbürlü ÖKGDD üretimi, bileşimi, içyapısı, 1sıl işlemi, avantaj/dezavantajları ve kullanım alanları hakkında ulusal literatürde eksik olan bilgi boşluğunu doldurmak, hem sanayiciye hem de araştırmacılara 1şık tutmak amacıyla yapılmıştır.

\section{Karbürlü östemperlenmiş KGDD}

\section{1 Üretim}

Karbürlü KGDD’in döküm işlemi geleneksel KGDD’in döküm yönteminden farklı değildir. Küreleştirme ve aşılama işlemleri bilinen yöntemlerle yapılabilir. Eğer karbürlü yapı döküm esnasında oluşturulacaksa, geleneksel dökümden farklı olarak belirli miktarlarda bazı karbür yapıcı alaşım elemanlarının ilavesi gereklidir. Döküm yapısında karbür içeren KGDD üretmek için geleneksel yönteme göre biraz daha dikkatli olmak gerekir. Çünkü katılaşma sırasında karbürlü küresel grafitli dökme demirde grafitin oluşmasıyla meydana gelen olumlu genleşme geleneksel KGDD'dekinden daha azdır. Sonuçta yapı KGDD'den daha çok temper dökme demire benzeyebilir. Eğer bu durum dikkate alınmazsa çekme problemleri ile karşılaşılabilir. Çekme boşluklarının varlığı özellikle darbe performansı olmak üzere karbürlü ÖKGDD'in mekanik özelliklerini olumsuz yönde etkiler [4].

Karbürlü ÖKGDD üretiminde kusursuz döküm elde etmek için karbon eşdeğeri $[\% \mathrm{C}+1 / 3(\mathrm{Si}+\mathrm{P})]$ kontrol altında tutulmalıdır. Tablo 1'de parça kesit kalınlığına bağlı olarak dikkate alınması gereken karbon eşdeğeri aralıkları verilmiştir.

Tablo 1. Parça boyutuna bağlı karbon eşdeğeri aralıkları [9].

\begin{tabular}{|l|l|}
\hline Kesit kalınlığ $1(\mathrm{~mm})$ & Karbon eşdeğeri aralığ 1 \\
\hline $0-13$ & $4,4-4,6$ \\
\hline $13-51$ & $4,3-4,6$ \\
\hline$>51$ & $4,3-4,5$ \\
\hline
\end{tabular}

Alaşım elemanı ilavesi yapıldığında özellikle küre sayısı dikkate alınmalıdır. Düşük küre sayısı grafit küreleri arasındaki boşluğun artmasına ve alaşım elemanlarının toplandığı daha büyük segregasyon bölgelerinin oluşmasına neden olur. En kötü ihtimalle bu bölgeler aşırı segregasyon içerdiklerinden östemperleme sırasında tamamen dönüşüme uğramazlar ve düşük karbonlu östenit veya martensit bile oluşumuna sebep olabilirler [9].

\subsection{Bileşimin etkisi ve iç yapı}

Karbürlü ÖKGDD'e, iç yapısında karbür oluşumunu sağlamak amacıyla başta Cr olmak üzere Mo, Mn ve V gibi karbür yapıcı elementler ilave edilebilir. Bunların yanısıra KGDD'in matris yapısını ve östemperlenebilirliğini geliştirmek amacıyla $\mathrm{Cu}$ ve $\mathrm{Ni}$ gibi alaşım elementleri de ilave edilebilir. Magnezyum oranının \%0,03-0,05 aralığında tutulması önemlidir. Bu miktardan daha düşük $\mathrm{Mg}$ oranı grafitin lamel şeklinde, daha 
büyük oranı ise patlamış grafit şeklinde oluşmasına sebep olacaktır[9]. Konu ile ilgili önceki çalışmalardan derlenen karbürlü ÖKGDD’in kimyasal bileşimine örnekler Tablo 2'de verilmiştir.

Tablo 2. Karbürlü ÖKGDD’e ait örnek kimyasal bileşimler.

\begin{tabular}{|l|l|l|l|l|l|l|l|l|l|l|}
\hline$\% \mathrm{C}$ & 2,70 & 1,60 & 3,593 & 3,272 & 3,47 & 3,6 & 3,5 & 3,77 & 2,45 & 3,34 \\
\hline \% Si & 1,90 & 2,07 & 2,705 & 2,745 & 2,57 & 1,9 & 2,85 & 2,76 & 1,8 & 2,67 \\
\hline \% Mn & 0,58 & 0,53 & 0,50 & 0,458 & 1,577 & 0,64 & 0,35 & 1,277 & 0,88 & 0,46 \\
\hline$\% \mathrm{~S}$ & 0,009 & 0,006 & 0,009 & 0,008 & 0,042 & 0,012 & 0,025 & 0,026 & 0,014 & 0,026 \\
\hline$\% \mathrm{P}$ & 0,026 & 0,024 & 0,038 & 0,034 & 0,038 & 0,029 & 0,08 & 0,049 & 0,03 & 0,03 \\
\hline$\% \mathrm{Cr}$ & 2,30 & 2,17 & 0,63 & 0,980 & --- & 4,3 & 0,75 & 0,596 & 2,42 & 0,42 \\
\hline$\% \mathrm{Cu}$ & 0,60 & 0,68 & 0,406 & & --- & 0,61 & 0,65 & 0,561 & 0,55 & 0,49 \\
\hline$\% \mathrm{Ni}$ & 0,488 & 0,458 & 0,008 & 0,010 & --- & 0,431 & --- & --- & 0,52 & --- \\
\hline$\% \mathrm{Ti}$ & 0,011 & 0,008 & --- & --- & --- & 0,016 & --- & --- & --- & --- \\
\hline$\% \mathrm{Mg}$ & 0,045 & 0,041 & 0,046 & 0,039 & 0,055 & 0,044 & 0,04 & --- & --- & --- \\
\hline$\% \mathrm{Mo}$ & --- & --- & 0,013 & 0,018 & --- & --- & --- & 0,570 & --- & 0,32 \\
\hline$\% \mathrm{~B}$ & --- & --- & --- & --- & 0,035 & --- & --- & --- & --- & --- \\
\hline$\% \mathrm{~V}$ & --- & --- & --- & --- & --- & --- & --- & --- & --- & 0,71 \\
\hline $\mathrm{CE}$ & 3,34 & 2,29 & 4,507 & 4,198 & --- & 4,23 & --- & --- & --- & --- \\
\hline Kaynak & {$[10]$} & {$[11]$} & {$[8]$} & {$[8]$} & {$[12]$} & {$[13]$} & {$[14]$} & {$[15]$} & {$[7]$} & {$[3]$} \\
\hline
\end{tabular}

Karbürlü ÖKGDD bileşiminde \%1,5 veya daha fazla oranda $\mathrm{Cr}$ bulunduğunda, matris aşınmaya karşı önemli oranda güçlenir[5]. Cr ilavesi dengeli ve yarı dengeli ötektik sıcaklıkları arasındaki farkı azaltarak karbür çökelmesini sağlar. Ayrıca Cr ilavesi ferrit hacim oranını azaltır, perlit hacim oranını arttırır [16].

Bor elementi de karbür oluşturmak amacıyla kullanılabilir. İlave edilecek bor miktarı çok küçük değerlerde olmalıdır. Çünkü artan B miktarı ile grafitin küreselleşmesi bozulur. Bor elementinin içyapı ve mekanik özelliklere etkisinin incelendiği bir çalışmada[12], \% 0,05 B miktarından sonra grafit kürelerinin küresellikten uzaklaştığı, $\% 0,03 \mathrm{~B}$ miktarında yüksek sertlik ve yeterli darbe tokluğu elde edilmiştir.

Sun ve arkadaşları [14] az miktarda nano boyutlu seryum oksit ilavesi ile grafit kürelerinin ve karbürlerin inceldiği, ösferritik matrisi dengeleyen östenitin karbon miktarının arttığı sonucunu bulmuşlar. İçyapıdaki karbürlerin boyut ve hacim oranındaki değişimle sertlik ve mukavemetin arttığı ve karbürlerin yapıda ince dağılımıyla tokluğun arttığı sonucuna varmışlardır.

Molibden ve vanadyum da kuvvetli karbür yapıcı elementler olarak kullanılabilirler. Mo ilavesi ile iç yapıda aşınma direncini arttıran $(\mathrm{Cr}, \mathrm{Fe})_{7} \mathrm{C}_{3},\left(\mathrm{Cr}_{2.5} \mathrm{Fe}_{4.3} \mathrm{Mo}_{0.1}\right) \mathrm{C}_{3}$ ve $\left(\mathrm{Fe}_{2} \mathrm{Mo}\right) \mathrm{C}$ karbürleri oluşurken, vanadyum ile $(\mathrm{Cr}, \mathrm{Fe})_{3} \mathrm{C}$ ve $\mathrm{VC}$ karbürleri oluşur[3,15]. Han ve arkadaşları[15] artan Mo miktarı ile grafit kürelerinin azaldığını, perlit ve karbürlerin miktarlarının ise arttığını ifade etmişılerdir. Başka bir çalışmada[3], vanadyum miktarının \% 0-\% 0,71 aralığında arttığında, östemperlenmiş yapıda iğnesel ferritin boyutunun daha ince olup miktarının arttığı, artık östenit miktarının ise azaldığı ifade edilmiştir. 
Karbürlü KGDD'in döküm iç yapısında grafit, karbür, perlit ve/veya ferrit matris fazları bulunur (Şekil 1a ve 1c). Karbürlü ÖKGDD iç yapısında ise grafit küreleri, ösferritik yapı (ferrit + karbonca zengin ostenit) ve karbürler bulunur (Şekil 1b ve 1d).
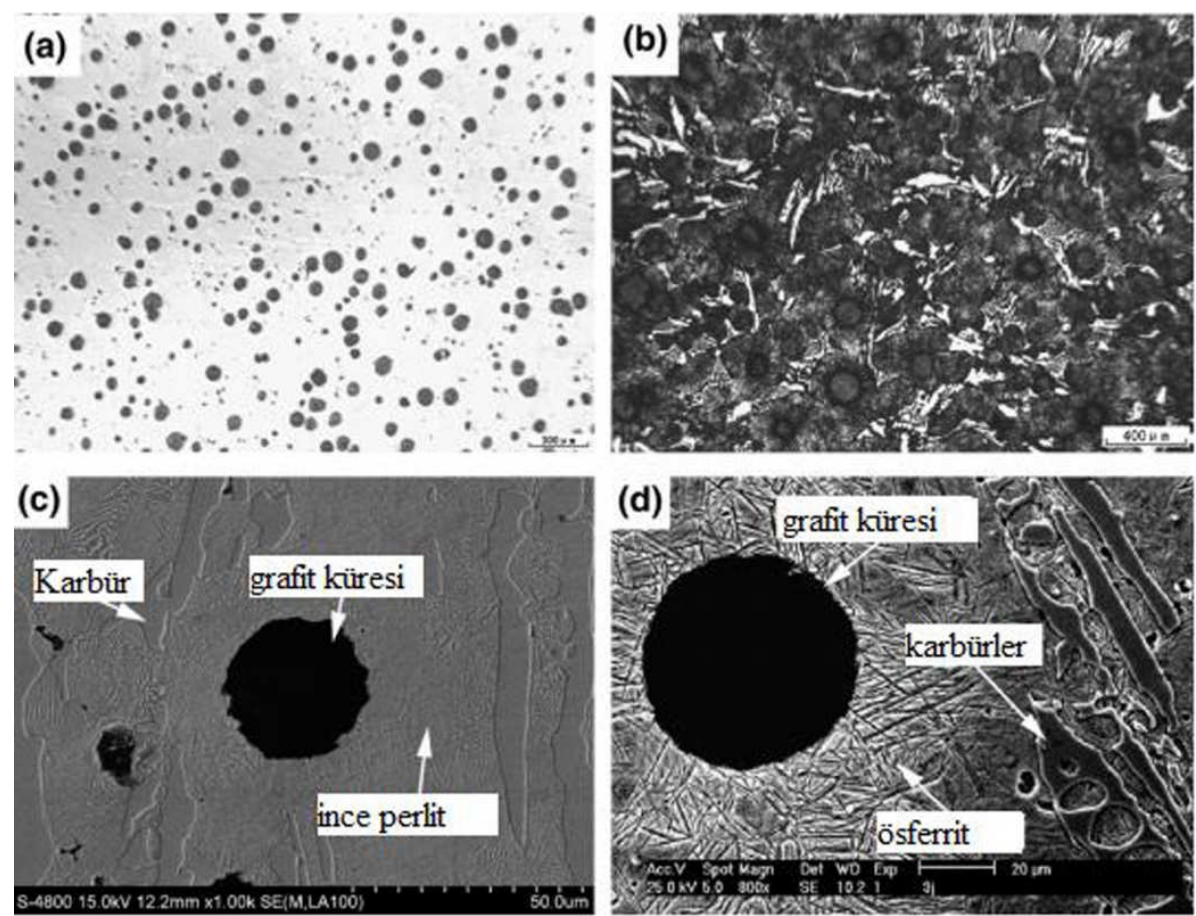

Şekil 1. Karbürlü KGDD iç yapısı a) Döküm hali 100X, b) Karbürlü ÖKGDD 100X, c) Döküm hali 1000X, d) Karbürlü ÖKGDD 800X [6].

\subsection{Karbür oluşturma yöntemleri}

Östemperlenmiş KGDD'in iç yapısında karbür oluşturmak için birkaç yöntem mevcuttur. Bunlar:

a) Döküm sonrasında dökme demirin yapısında karbür elde etmek için $\mathrm{Cr}, \mathrm{Mo}, \mathrm{Ti}, \mathrm{V}$, vb. gibi karbür yapıcı elementler ile alaşımlama yapılabilir. Katılaşma sırasında soğuma hızı kontrol edilerek karbür oluşumu sağlanabilir. Ayrıca, ötektikaltı bir bileşim oluşturmak için karbon eşdeğerini ayarlayarak döküm sonrası karbürlü KGDD yapısı elde edilebilir. Bu yöntemlerle elde edilen karbürlü KGDD'e uygun şartlarda östemperleme işlemi uygulanır. Optimum alaşım elemanı miktarı ve östemperleme sıcaklığı kombinasyonu seçilerek aşınma dayanımı ve darbe tokluğu arasında iyi bir denge sağlanabilir.

b) Östemperleme sırasında ikinci basamak reaksiyonu genişletilerek ösferritik yapıda bulunan yüksek karbonlu ostenitten ince dağılımlı karbür ayrışması sağlanabilir.

c) Kalıp boşluğunda istenen bölgelere ufalanmış $\mathrm{M}_{\mathrm{x}} \mathrm{C}_{\mathrm{y}}$ karbürleri mekanik olarak yerleştirilir. Ergimiş dökme demir kalıp boşluğunu doldurduğunda, sürekli bir demir matrisi içinde bölgesel karbürlü yapı gözlenir. Bu yöntem, parçanın sadece gerekli bölgelerinde karbür oluşumunu sağlar. Ardından uygulanan östemperleme işlemi ile bu bölgelerde aşınma dayanımlı karbürlü ÖKGDD elde edilir. 
d) Tamamen veya çoğunlukla ferritik matrisli dökme demirin aşınmaya maruz kalan yüzeyine sert yüzey kaynağı yapılır. İşlem sonucunda kaynak bölgesinde karbürlü yapı ile kaynak/parça arayüzeyinde isıdan etkilenen bölge gözlenir. Kaynaktan sonra uygulanan östemperleme işlemi, seçilen kaynak malzemesinin bileșimine göre kaynak bölgesine çok az etki eder veya hiç etki etmez. Bununla birlikte, ısıdan etkilenen bölge ortadan kalkar ve kaynak bölgesinin dışında tamamen ösferritik matris elde edilir [17].

\section{4 Östemperleme işlemi}

Östemperleme işlemi demir esaslı metallere üstün mekanik özellikler kazandırmak için uygulanan yüksek performanslı bir izotermal ısıl işlemdir. Bu işlemde dikkat edilmesi gereken en önemli husus malzemenin, perlit oluşumuna müsaade etmeyecek derecede hızla izotermal bir sıcaklığa soğutulmasıdır. Östemperleme işleminde soğutma ortamının sıcaklığı martensit başlama sıcaklığının üzerinde olması gerekir. Yani yapıda martensit oluşumu engellenmelidir. Malzeme östemperleme sicaklığında istenen iğnesel yapının oluşumuna yetecek süre bekletilir. Çeliklerde bu yapı iğnesel ferrit ve karbürden oluşan beynittir. Dökme demirlerde ise, yüksek silisyum içerikleri yüzünden bu yapıya ösferrit adı verilir. Ösferrit yapısı iğnesel ferrit ve karbonca zengin östenit (dengeli östenit) fazlarından meydana gelir. Östemperleme işleminin şematik gösterimi Şekil 2'de verilmiştir. Östemperleme işleminin işlem kademeleri [9]:

1. Östenitleme sıcaklığına 1sıtmak (A-B arası)

2. Östenitleme (B-C aras1)

3. Östemperleme sıcaklığına soğutmak (C-D arası)

4. Östemperleme sıcaklığında izotermal ısıl işlem (D-E arası)

5. Oda sicaklığına soğutmak (E-F arası)

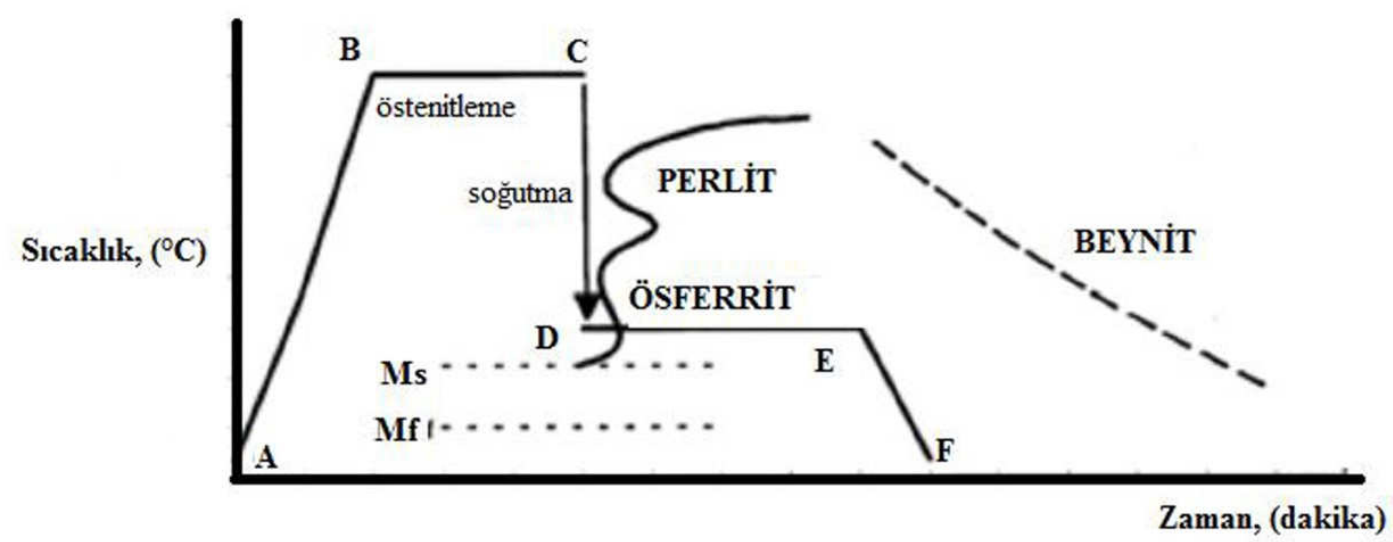

Şekil 2. Östemperleme işlemi şeması.

Karbürlü ÖKGDD'in östemperleme işleminin geleneksel ÖKGDD'e uygulanan östemperleme işleminden önemli bir farkı yoktur. Sadece kimyasal bileşime uygun olarak seçilen östenitleme sıcaklık ve süresinde farklılıklar olabilir. Östemperleme işleminde östenitleme sıcaklık ve süresinin doğru seçimi önemlidir. Bu sıcaklık ve süre karbonca zengin östenitin oluşması için yeterli olmalıdır. Fazla miktarda alaşım elementi içeren KGDD'in östenitlenmesi için daha uzun zamana ihtiyaç duyulabilir.

Karbürlü ÖKGDD'in östemperleme işleminde yağ içeren banyoların kullanımı uygun değildir. $240-400^{\circ} \mathrm{C}$ aralığında tuz banyoları kullanılır. Ösferritik yapı oluştuktan sonra 
östemperlemeye devam edilirse, ösferritik yapıdaki karbonca zengin östenit, ferrit ve karbüre ayrışır.

\section{Aşınma davranışı}

Karbürlü ÖKGDD' in aşınma direnci geleneksel ÖKGDD' in aşınma dayanımından önemli ölçüde daha yüksektir. Bunu sağlayan içyapıdaki sert ve aşınmaya dirençli karbür bileşikleridir. \%0,5 ve \%1,04Cr ilave edilerek içyapısında düşük ve yüksek karbür içeren ÖKGDD'in abrasif aşınma deneyleri sonucunda her iki orandaki karbürlü demirin geleneksel ÖKGDD'den daha az hacim kaybına uğrayarak daha üstün aşınma direnci gösterdiği görülmektedir(Şekil 3a) [4]. Ösferrit matris içinde dağılmış karbürlerin bu üstünlüğü sağladığı ve karbür miktarı arttıkça hacim kaybının azalarak aşınma direncinin de arttığı gözlenmektedir.

Şekil 3b'de düşük ve yüksek karbürlü ÖKGDD ile yüksek krom içerikli abrasif aşınma dirençli dökme demirlerin aşınma deneyleri sonucunda elde edilen hacim kayıpları karşılaştırmalı olarak verilmiştir. Karbürlü ÖKGDD'ler, özellikle $50 \mathrm{HRc}$ sertliğinin altında, abrasif aşınmaya karşı iyi direnç gösteren bu malzemelerle de kıyaslanabilir değerlere sahiptirler. Bu sertlik değerinin üzerinde abrasif aşınma dirençli malzemeler karbürlü ÖKGDD'e göre bir miktar daha az hacim kaybıyla biraz daha iyi aşınma direncine sahiptirler [4].
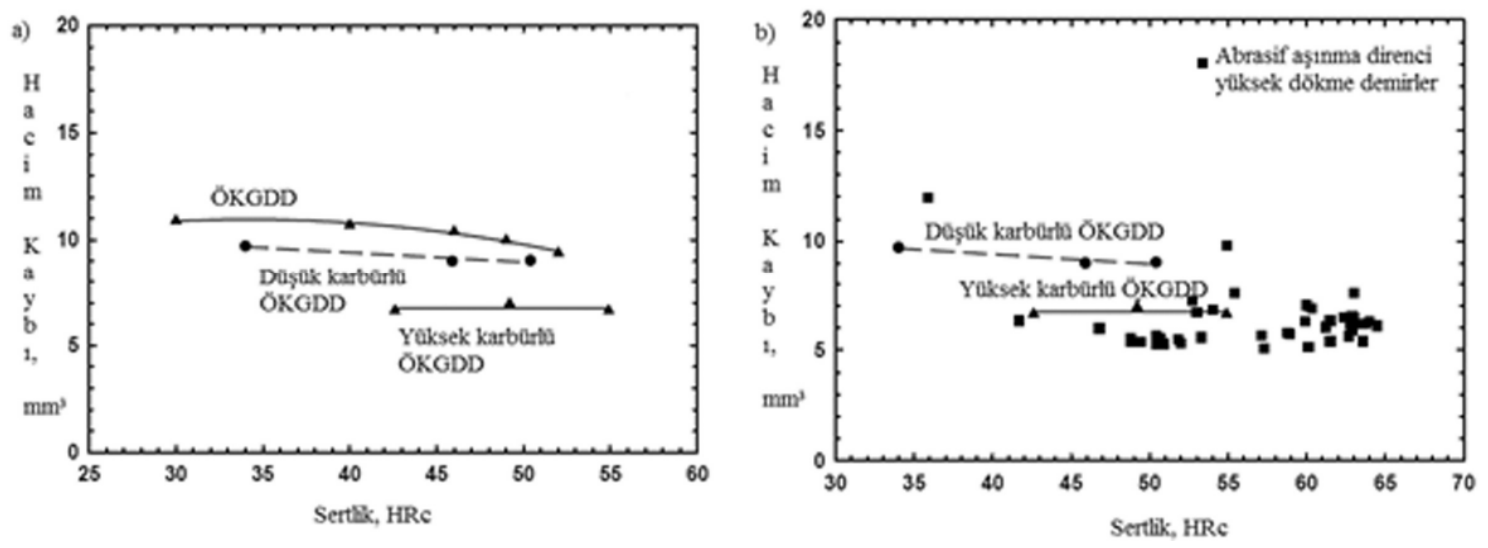

Şekil 3. Yüksek ve düşük karbürlü ÖKGDD'in a) Geleneksel ÖKGDD ve b) Abrasif aşınma direnci yükssek dökme demirler ile karşılaştırmalı abrasif aşınma deney sonuçları [4].

\section{Avantaj/ Dezavantaj ve kullanım alanları}

Avantajları:

- En iyi aşınma dayanımlı ÖKGDD'den daha üstün aşınma dayanımına sahiptir.

- \%18 Cr'lu beyaz dökme demirden daha ucuz ve daha toktur.

- Üretimleri için dökümhanelerde ek yatırım yapılmasına gerek yoktur.

- Mn çeliklerine eşit veya düşük maliyette alternatif bir malzemedir.

- \% 18 Cr'lu beyaz dökme demire daha düşük maliyetle alternatiftir.

Dezavantajları:

- Karbürlü yapılarından dolayı sınırlı işlenebilirliğe sahiptirler. 
- Karbür oluşumu için alaşımlama yapılmışsa hurdalar dikkatli kullanılmalı.

- Karbürler döküm yoluyla oluşturulursa ilave işlem ve maliyetle karşılaşılabilir [17].

Karbürlü ÖKGDD'in ilk kullanımı tarımsal alanda olmak üzere; artan çalışmalar sonucunda otomotiv, tren yolu, yapı, maden gibi pek çok mühendislik uygulamalarında da kullanılmaya başlanmıştır. Kam milleri, sübap iticileri, pompa bileşenleri, aşınma plakaları, haddeleme ve kumlama parçaları [17,18], süspansiyon bileşenleri, ekskavatör dişlileri, kazıyıcılar, değirmen çekici, harman döveni, vb.[4] önemli kullanım alanlarına örnekler olarak verilebilirler. Devam eden çalışmaların sonuçlarıyla birlikte bu kullanım alanlarının daha da çoğalması beklenmektedir.

\section{Kaynaklar}

[1] Patil, S.A., Pathak, S.U. ve Likhite, A., Development and wear analysis of carbidic austempered ductile iron (CADI), International Journal of Innovative Research in Science Engineering and Technology, 3, 2, 9652-9657, (2014).

[2] Lagarde, M., Basso, A., Dommarco, R.C. ve Sikora, J., Development and characterization of a new type ductile iron with a novel multi-phase microstructure, ISIJ International, 51, 4, 645-650, (2011).

[3] Han, C.F., Sun, Y.F., Wu, Y. ve Ma, Y.H., Effects of vanadium and austempering temperature on microstructure and properties of CADI, Metallography, Microstructure and Analysis, 4, 135-145, (2015).

[4] Hayrynen, K.L. ve Brandenberg, Carbidic austempered ductile iron (CADI)- the new material, Transactions of the American Foundry Society, 111, 3, 845-850, (2003).

[5] Laino, S., Sikora, J.A. ve Dommarco, R.C., Development of wear resistant carbidic austempered ductile iron (CADI), Wear, 265, 1-7, (2008).

[6] Cheng, P.Y., Jin, J.H., Hai, L.J. ve Lu, L.G., Influence of cooling rate on the microstructure and properties of a new wear resistant carbidic austempered ductile iron (CADI), Materials Characterization, 72, 53-58, (2012).

[7] Likhite, A., Parhad, P., Peshwe, D.R. ve Pathak, S.U., Effect of austenization temperature on wear behavior of carbidic austempered ductile iron (CADI), International Scholarly and Scientific Research and Innovation, 8, 2, 510512, (2014).

[8] Dhanapal, P. ve Nazirudeen, M., Parameter optimization of carbidic austempered ductile iron using taguchi method, International Journal of Engineering Science and Technology, 2, 8, 3473-3482, (2010).

[9] Dhanapal, P. ve Ibrahim, A.S., Production of carbidic austempered ductile iron (CADI), International Conference on Systems, Science, Control, Communication, Engineering and Technology, 527-535, (2016).

[10] Gutte, J. ve Patil, S.A., Effect of $2.3 \mathrm{Cr} \%$ and austempering parameters on properties of carbidic austempered ductile iron (CADI), International Journal for Scientific Research and Development, 4, 4, 1039-1042, (2016).

[11] Dangra, P. Patil, S. ve Harne, M., Effect of austenizing temperature on the wear properties of CADI, International Journal of Science and Engineering, 3, 96103,(2015). 
[12] Peng, Y.C., Jin, H.J., Liu, J.H. ve Li, G.L., Effect of boron on the microstructure and mechanical properties of carbidic austempered ductile iron, Materials Science and Engineering A, 529, 321-325, (2011).

[13] Pandit, P.L. ve Patil, S.A., Effect of WEDM parameters on MRR of carbidic austempered ductile iron, International Journal of Science and Research, 4, 6, 384-387, (2015).

[14] Sun, X., Wang, Y., Li, D.Y. ve Wang, G., Modification of carbidic austempered ductile iron with nano ceria for improved mechanical properties and abrasive resistance, Wear, 301, 116-121, (2013).

[15] Han, C.F., Wang, Q.Q., Sun, Y.F. ve Li, J., Effects of molybdenum on the wear resistance and corrosion resistance of carbidic austempered ductile iron, Metallography, Microstructure and Analysis, 4, 298-304, (2015).

[16] Ovalı, I., Kılıçlı, V. ve Erdoğan, M., Production of surface chilled ductile iron, Materialwissenschaft und Werkstofftechnik, 46, 9, 949-961, (2015).

[17] Nofal, A.A. ve Jekova, L., Noval processing techniques and applications of austempered ductile iron, Journal of the University of Chemical Technology and Metallurgy, 44, 3, 213-228, (2009).

[18] Nofal, A.A., The current status of the metallurgy and processing of austempered ductile iron (ADI), Proceedings, 10th International Symposium, Science and Processing of Cast Iron, 69-82, Mar del Plata, (2014). 